\title{
Munchausen's Syndrome: Towards a Psychodynamic Understanding
}

\author{
Sharon Riser, MD \\ Thomas Jefferson University Hospital
}

Follow this and additional works at: https://jdc.jefferson.edu/jeffjpsychiatry

Part of the Psychiatry Commons

Let us know how access to this document benefits you

\section{Recommended Citation}

Riser, MD, Sharon (1985) "Munchausen's Syndrome: Towards a Psychodynamic Understanding," Jefferson Journal of Psychiatry. Vol. 3 : Iss. 1 , Article 4.

DOI: https://doi.org/10.29046/JJP.003.1.001

Available at: https://jdc.jefferson.edu/jeffjpsychiatry/vol3/iss1/4

This Article is brought to you for free and open access by the Jefferson Digital Commons. The Jefferson Digital Commons is a service of Thomas Jefferson University's Center for Teaching and Learning (CTL). The Commons is a showcase for Jefferson books and journals, peer-reviewed scholarly publications, unique historical collections from the University archives, and teaching tools. The Jefferson Digital Commons allows researchers and interested readers anywhere in the world to learn about and keep up to date with Jefferson scholarship. This article has been accepted for inclusion in Jefferson Journal of Psychiatry by an authorized administrator of the Jefferson Digital Commons. For more information, please contact: JeffersonDigitalCommons@jefferson.edu. 


\title{
MUNCHAUSEN'S SYNDROME: TOWARDS A PSYCHODYNAMIC UNDERSTANDING
}

\author{
SHARON RISER, M.D.
}

\section{INTRODUCTION}

The third edition of the Diagnostic and Statistical Manual of Mental Disorders cites two essential criteria for the diagnosis of chronic factitious disorder with physical symptoms, more poetically known as Munchausen's Syndrome:

a) Plausible presentation of physical symptoms that are apparently under the individual's voluntary control to such a degree that there are multiple hospitalizations;

b) The individual's goal is apparently to assume the "patient" role and is not otherwise understandable in light of the individual's environmental circumstances (1).

Additionally noted is the frequent occurrence of a true physical illness entailing extensive hospital treatment during the childhood or adolescence of these patients, as well as the horrific incapacitation of the disorder due to a chronic course of repeated hospitalizations. Munchausen's Syndrome is apparently more common in males than females, but the prevalence is in question. Some authors claim it is ubiquitous, but rarely recognized. Others believe it to be rare because certain cases are continually overreported (1).

This paper presents a summary of the hospital course of a Munchausen patient recently treated by a psychiatric consultant in a community general hospital. Major themes and an historical perspective of the thinking regarding the psychodynamics of this intriguing illness will follow.

\section{CASE REPORT}

A twenty-nine-year-old white female was brought by ambulance to the emergency room with a history of suddenly falling to her knees at a local bus terminal and being unable to rise thereafter. The patient stated that she was an intensive care unit nurse at a nearby university hospital and reported sustaining an acute lower back injury while changing a tire several days prior to admission. A past history of numerous surgical procedures included a lumbar laminectomy, left shoulder and bilateral knee operations. The patient also reported being frequently prescribed narcotics due to the pain incurred with these procedures.

Dr. Riser is a second-year resident. 
Upon examination the patient complained of lower back pain extending into the right buttock and leg, as well as weakness and paresthesia of the right leg. Twenty-four hours after admission she reported worsening numbness and a decrease in mobility of both lower extremities. Lack of any documented urine output within this period was of additional concern. An emergency computerized tomography scan of the lower spine was performed, but was without diagnostic value due to artifact from residual Pantopaque ${ }^{\circledR}$ in the spinal canal and recurrent patient movement. A myelogram was not performed because of the patient's assertion that she was iodine allergic. Due to the perceived deterioration in her neurological status, an emergency thoracic laminectomy was performed with pre-operative diagnosis being "ruptured thoracic disc." In that no abnormality was found at the time of surgery, the post-operative diagnosis read "questionable spinal cord compression."

During the post-operative period the patient was without neurological improvement, appearing to be unable to move her legs with persistence of a thoracic sensory level. Despite repeated attempts to persuade the patient to have a myelogram performed with appropriate prophylactic measures, she refused, offering a medically sophisticated explanation of a previous anaphylactic reaction to the preparation.

By post-operative day four it was documented that the patient had a bizarre lack of concern regarding her paralysis, often displaying an inappropriately jocular affect. The ensuing days yielded an unenlightening cystometrogram, lumbar puncture, and intrathecal cisternogram. An isotope myelogram and nuclear magnetic resonance study failed to demonstrate a spinal canal blockage.

The patient's behavior became demanding, manipulative, and at times abusive. She adeptly pitted nurse against physical therapist, and doctor against consultant, while pilfering cigarettes, money, and telephone use from patients and visitors. She received intramuscular meperidine for 25 days post-operatively until a consultant questioned its continuance. Despite the patient's assertions, she was without visitors and created havoc on adjacent floors. Disgruntled with her care, she requested a transfer to either a university hospital or a spinal cord rehabilitation center.

As consultation psychiatry and social service became involved in the case, it was gradually learned that the patient's professed identify was a fabrication. Her plausible story of being a nurse with a supportive boyfriend and close family network was a tragic blur of fantasy and falsehood. The patient's adoptive father related being contacted by innumerable hospitals "from Richmond, Virginia to Nyack, New York" where his daughter had simulated imaginative "emergencies" and secured multiple unnecessary surgeries, often posing as a health professional. When not hospitalized in the past several years, she "free-loaded" and stole from acquaintances.

A brief psychosocial history revealed that the patient had been put up for adoption by her biologic parents at the age of two for unknown reasons. The adoptive parents were informed that the child had been hospitalized for several months in her first year of life, at least in part for neonatal jaundice. At the time of adoption the new parents greeted a child with extensive scratches, bruises, and bitten fingers and toes. They soon discovered that the child demonstrated such self-mutilative behavior when frustrated. She matured into a gregarious youth, "always the life of the party," with many 
acquaintances but few friends. Despite an obviously keen intellect, the patient was a low achiever, leaving high school in the tenth grade. She became involved in narcotic abuse as a teenager, routinely presenting to emergency rooms feigning pain to obtain medication. At one point she was expelled from a methodone maintenance program for continued street drug use. The patient was married briefly and has a five-year-old daughter who is cared for by her former husband, with whom she has minimal contact.

After the diagnosis of Munchausen's Syndrome was established, the patient refused to consider transfer to a psychiatric facility and continued to simulate paralysis. She became increasingly disruptive and incited the anger of most of the staff involved in her care. While threatening to leave the hospital daily, she orchestrated a plan to be discharged to the home of her hospital roommate. Following forty-four days of hospitalization the patient walked out of the facility without assistance. It was later learned that she had been admitted to the intensive care unit of a nearby hospital on the very same day for "ascending paralysis."

\section{HISTORICAL PERSPECTIVE}

Although reference to self-inflicted disease dates back to biblical times, it was not until 1843 that Gavin differentiated malingerers, those with identiflable social or economic gain, from patients who simulate illness for no apparent reason other than their "unaccountable gratification in deceiving physicians and others" (2). It was one hundred years later that Karl Menninger's "Polysurgery and Polysurgical Addiction" further detailed this distinction in presenting case histories and psychodynamic formulations of several individuals who had unnecessarily endured multiple surgical procedures.

"Though explicitly recognized by Gavin and implicitly discussed by Menninger, the Munchausen's Syndrome went unnamed until Asher's classic article of 1951" (2). As intriguing as the syndrome itself is the tale of its namesake, the colorful German raconteur, Baron Karl Friedrich Hieronymus von Munchausen (1720-1797). Retired at an early age from an unremarkable military career, the baron frequently entertained guests with captivating yet improbable accounts of his exploits and heroic deeds in the Russian cavalry. It was Rudolph Eric Raspe, a chance dinner companion, who immortalized the baron and brought him to a tormented life of notoriety when he anonymously published Baron Munchausen's Narrative of his Marvellous Travels and Campaigns in Russia. It is of historical note that Raspe, who was an accomplished academician and journalist while a guest of the Baron, wrote the narrative more than a decade after their meeting as a fugitive in England. It had been discovered that the esteemed professor had stolen valuable antiques from a collection he was overseeing for a German nobleman, at which time he escaped the police and fled to London. Munchausen died a recluse, "but he never learned who had made him world-famous and thus had ruined him" (3).

"Like the tragic baron, the patient with Munchausen's Syndrome travels widely from hospital to hospital, reciting tall tales about his illnesses that convince physicians 
of the need for treatment" (2). Asher accurately described the typical hospital course of such a patient which begins with an "organic emergency" dramatically presented, followed by the discovery of an astounding number of previous hospital admissions frought with deception, and an abrupt discharge of the patient against medical advice after violent quarreling with both doctors and nurses. Diagnostic "pointers" offered by Asher included a multiplicity of surgical scars, an evasive and truculent demeaner, an acute and harrowing but not entirely convincing admitting history, and "a wallet or handbag stuffed with hospital attendance cards, insurance claims forms and litigious correspondence" (4). Past history of drug addiction, psychiatric treatment, and prison sentence were also considered part of the picture. Three major varieties of the syndrome were detailed: the abdominal, hemorrhagic and neurological types.

Well described by Asher is the creative weave of fact, falsehood, and fantasy which unravels when the patient's true identity is revealed. Despite "the duplicity and distortion," he warned his fellow physicians that these patients are often quite ill. $\mathrm{He}$ noted with amazement that for no identifiable gain they tolerate "the more brutish hospital measures" (4), all the while spinning lies of astounding proportion (pseudologica fantastica). This is well illustrated in the above case report in which the patient prompted multiple painful diagnostic procedures, as well as her second unnecessary laminectomy.

Asher speculated on some possible behavioral motives of these patients, which included: a desire to be the center of attention, a grudge against physicians and hospitals, drug addiction, refuge from police, and a desire for free food and shelter. Yet Asher felt there must be some "strange twist of personality" or "psychological kink," if not the presence of frank schizophrenia, masochism and or psychopathy to produce such severe pathology (4).

It was Chapman, in 1957, who angrily warned American physicians of the preregrinating problem patient "who spends his time going from place to place, resulting in wide travels, and presenting himself to hospitals with a fanciful history and extraordinary complaints" (5). Chapman added a forth Munchausen variety, the cutaneous type, to the three previously coined by Asher. He suggested that these patients might be the victims of medical mismanagement, and unnecessary or unsuccessful procedures, and that the behavior pattern evolved "represents a psychopathic accretion built upon the victim's reactions to recurrent symptoms of a frightening nature" (5). This author advocated alerting one's colleagues to Munchausen patients through publication of their histories in the medical press, and permanently confining such individuals to mental hospitals for custodial care.

Reporting on three neurological cases in 1958 (and offering yet another eponym-hospital hoboes), Clarke and Melnick erroneously speculated that the syndrome might be a product of free health care delivery. They did, however, rightly emphasize the need to be wary of true organic signs which "are usually congenital or of a chronic nature and help to trap the unwary and make a complex clinical picture even more perplexing" (6). Interestingly our patient had chronically elevated liver enzymes, which confounded her clinical presentation and almost resulted in another invasive procedure. 
Despite the frustration and anger that these "bands of hoaxers" incite, Clarke and Melnick stressed the need to view them as sick individuals with masochistic traits in need of treatment.

\section{PSYCHODYNAMIC CONSIDERATIONS}

When interest shifted from the purely phenomenologic and medical to the psychiatric realm, the dynamics of Munchausen patients began to be explored through an understanding of the hostility and contempt evoked in the staff who treat them. Stating that the variety of symptoms presented by these patients is limited only by their medical sophistication and "the symbolic meaning of the choice of organ through which the simulation is expressed" (7), Bursten stressed three major features of the illness: dramatic presentation of complaints, pseudologica fantastica, and incessant wandering as a way of life. "What could possibly motivate a person to wander from place to place seeking brief hospital admissions and painful procedures under false pretenses, not as an occassional frantic search for help but as a way of life?" (7) $\mathrm{He}$ suggested that the answer must go beyond sociopathy, and likened Munchausen patients to imposters who have unattainable ego ideals "and use their imposture as a means of defense against the anxiety associated with feelings of inferiority" (7). Thus, when the patient's "defective" identity is revealed, intense anxiety surfaces and he must flee. Through this incessant wandering his true identity is never assumed. Unlike the usual imposter, who poses as a man of influence and prestige, the masochistic Munchausen patient in Bursten's formulation takes a counterphobic stance by posing as the defective, inadequate victim in need of help. He masters the fear by rising above it. "In the masochistic defense he reverses roles and identifies with the aggressor-in this case the physician" (8). The wish to be the physician is often quite tangible, as evidenced by our patient, who characteristically posed as a nurse or medical student. The patient appears to submit to the physician, but in fact has defiantly orchestrated the entire scenario.

Progressing from Simmel's work, Bursten suggested that the Munchausen patient chooses to act out his sexual and aggressive impluses within the medical field due to unresolved oedipal conflicts which easily lend themselves to the doctor-patient relationship. Taking this argument a step further, Spiro described three principles through which imposters, compulsive wanders, and Munchausen patients psychodynamically converge:

a) A history of preoedipal deprivation;

b) Discrepancy between ego ideal and self image, particularly with regard to a fancied defective genital development; and

c) Mastery over early trauma.

Attempting to resolve early frustration and trauma the patient seeks love and approval from the symbolic object (the hospital or physician), "as well as revenge through superiority and hostility expressed by the knowledge of the deception" (9). He relentlessly recreates early experience with illness and hospitalization, and masters the 
conflict by controlling the production and termination of the illness, with ultimate control reasserted by his characteristic leave against medical advice. The early childhood of these compulsive wanderers is characterized by emotionally distant caretakers. The wandering represents the search for closeness with the caretaker (symbolized by medical facilities and physicians), and the inability to accept such intimacy. Yet through masochistic submission to painful testing and procedures he temporarily maintains a closeness with the sadistic primary love object. "The powerful impact of an aloof, hostile parent figure may persist and be dealt with in the guise of rebellious yet masochistic relationship with a large institution ... the hospital, with its mixture of care and pain, of attention and fear, of dependency and rejection, is an effective substitute" for the traumatizing ambivalent parent (9).

Cramer and associates, in their description of four long-term pathomimes, suggested that an important element in the development of a Munchausen patient is the actual presence of a physician as a parental or authority figure during childhood who becomes a selected object with whom love and anger is acted out. The repeatedly sought physician-patient relationship caricatures this dyad. This is a somewhat different perspective than that already presented, in which the masochistic imposter symbolically choses the medical field in an attempt to resolve preoedipal trauma. These authors also commented on the large number of such patients who work in paramedical fields "in an attempt to identify with the idealized, caretaking, parent-like physician" (10). By assuming the nurturing role themselves, they can deny their own dependent and passive wishes, while maintaining a close relationship with a physician. Identification with the active role collapses, however, when rejection or frustration revives sadistic wishes against the abandoning parent. The patient must then reestablish a passive dependency on the love object. This aggression is intense and "is dealt with by turning it against the self (by operations and suicide attempts) and by projecting it upon the physician who is seen as a careless rejecting and sadistic agent" (10). "The covert identification with the physician remains and is expressed in the patient's use of medical terminology, denigration of previous physicians, and attempts to show superiority" (8).

It takes two to act out a sadomasochistic drama. As our medical omnipotence is mocked by the patient's deception, we reflexively respond with the very emotions the patient seeks to elicit. "If this is a flight forward into what the patient fears, then the physician's willingness to treat his subsequent anger and desire to punish, allow the patient justly to accuse the physician of sadism in operating and negligence in rejecting him" (8). I am reminded of the story of a physician who went out of his way to become involved in the case of a Munchausen patient, proudly boasting of his order to handcuff her wheelchair to her bedpost and his influence in prompting her to leave against medical advice!

Psychiatrists have just begun to elucidate this illness with its chronic human suffering and costly medical toll. The implications of the proposed psychodynamics for treatment of the disorder, its distinction from malingering and hysterical conversion symptoms, and the tenuous position factitious illness straddles between the psychiatric and medical specialities, are further topics to be explored. Once a physician encounters 
a patient with Munchausen's Syndrome the experience is rarely forgotten and the need for a better understanding of this bewildering drama in which we play a leading role becomes obvious.

\section{REFERENCES}

1. Diagnostic and Statistical Manual of Mental Disorders, 3rd edition. Washington, American Psychiatric Association Press, 1980

2. Hyler S, Sussman N: Chronic factitious disorder with physical symptoms (the Munchausen syndrome). Psych Clin N Am 4: 365-377, 1981

3. Ludwig J, Mann R: Münchhausen vs. Munchausen. Mayo Clin Proc 58: 767-769, 1983

4. Asher R: Munchausen's syndrome. Lancet I:339-341, 1951

5. Chapman J: Peregrinating problem patients-Munchausen's syndrome. JAMA 165: 927933, 1957

6. Clarke E, Melnick S: The Munchausen syndrome or the problem of hospital hoboes. Am J Med 25: 6-12, 1958

7. Bursten B: On Munchausen's syndrome. Arch Gen Psych: 13: 261-268, 1965

8. Swanson D: The Munchausen's syndrome. Am J Psychother 35: 436-444, 1981

9. Spiro H: Chronic factitious illness, Munchausen's syndrome. Arch Gen Psych 18: 569-579, 1968

10. Cramer B, Gershberg M, Stern M: Munchausen syndrome. Arch Gen Psych 24: 573-578, 1971 